\title{
Cidade Um Computador por Aluno - UCA Total A identificação de situações inclusivas na totalidade
}

\author{
Mstanda. Fernanda Chagas Schneider UFRGS/CNPq - ferchsc@yahoo.com.br \\ Dra.Lucila Maria Costi Santarosa - UFRGS/CNPq - lucila.santarosa@ufrgs.br \\ Dra. Debora Conforto - SMED/CNPq - conforto@terra.com.br
}

\section{Resumo}

Este artigo busca uma aproximação entre a Política Nacional de Educação Inclusiva e o PROUCA, ambos operam sob a lógica da inclusão, a primeira enfocando a inclusão escolar e, a segunda, a inclusão digital. Para tanto, iniciou-se uma pesquisa qualitativa, descritiva em formato de estudo de caso, observando a realidade da cidade UCA Total de Tiradentes-MG. Nesta primeira etapa, realizou-se uma observação "in loco" visando identificar as situações de inclusão. Além disso, entrevistas foram realizadas com os professores e gestores municipais no intuito de identificar quais movimentos estão sendo desencadeados para que o PROUCA abarque a diversidade em contexto regular de ensino. Os resultados parciais apontam fragilidades no processo de implementação do projeto tornando a totalidade inclusiva uma meta ainda distante de ser alcançada.

Palavras-chave: Inclusão, Informática na Educação, Um Computador por Aluno

\section{One Laptop per Child City - UCA Total The identification of all inclusive situations}

\begin{abstract}
This paper intends to promote an approximation between the Inclusive Educational National Policy and the PROUCA. Both operate under the logic of inclusion, the first one focusing on school inclusion and the second one on the digital inclusion. For this purpose a qualitative descriptive research has been initiated in the form of a case study, with the observation of the reality of the one laptop per child in the whole city project, in TiradentesMG. In this first phase, the observation was performed "in loco" aiming at the identification of the inclusion situations. Besides that, the teachers the Educational authorities of the city were interviewed in order to identify which movements have been promoted for the PROUCA to comprehend de diversity within the regular school context. The partial results indicate some weaknesses in the implementation process of the project, which makes the inclusive totality a goal still far from being fulfilled.
\end{abstract}

Key words: Inclusion, Computers in Education, One Laptop per Child

\section{A Política de distribuição de Um Computador por Aluno - UCA}

Esta política nasce observando os preceitos do projeto One Laptop per Child $^{1}$ (OLPC), idealizado pelo pesquisador Nicholas Negroponte ${ }^{2}$, tal projeto convidava os diversos países a engajarem-se num esforço de democratização e universalização do acesso as TICs, tomando como propulsão a garantia de

\footnotetext{
${ }^{1}$ A OLPC é uma associação sem fins lucrativos, criada por pesquisadores do Media Lab do MIT (Massachusetts Institute of Technology) em 2001. Foi criada no intuito proporcionar a disseminação de laptops educacionais a baixo custo

${ }^{2}$ Cientista Norte Americano, professor do Massachusetts Institute of Technology (MIT). É mundialmente conhecido por defender a disseminação de computadores portáteis a baixo custo.
} 
que todas as crianças em idade escolar venham a ter acesso a um computador próprio.

"Nossa missão é oferecer oportunidades educacionais para as crianças mais pobres do mundo, dando a cada uma dela um laptop robusto, de baixo custo, com baixo consumo de energia, conectado à Internet, bem como ferramentas projetadas para a colaboração e a aprendizagem."(http://one.laptop.org/about/mission/.)

No Brasil, foi instituído um grupo interministerial para avaliação da proposta e apresentação de um relatório de viabilidade de implementação. Definiu-se, em contexto brasileiro, denominar este projeto como "Um Computador por Aluno" (UCA). Realizou-se então a fase experimental, a chamada "pré-piloto" onde inicialmente 5 escolas foram selecionadas em cidades de diferentes estados. São Paulo-SP, Porto Alegre-RS, Palmas-TO, Piraí-RJ e Brasília-DF foram às primeiras cidades a serem contempladas.

Como forma de avaliar este processo de implantação da Política Publica o Conselho de Altos Estudos e Avaliação Tecnológica (CAEAT) da Câmara dos Deputados produziu um estudo que teve como objetivo identificar aspectos que poderiam orientar as ações na segunda fase do projeto, bem como sistematizar aprendizagens que subsidiassem a disseminação de laptops como ferramentas de apoio à educação. Após a visualização dos resultados parciais o governo organizou algumas ações que oportunizassem a continuidade da implantação do projeto. O PROUCA entra então em sua segunda fase, denominada Piloto. Esta visa atender 300 escolas em todo o território nacional além de 6 municípios em totalidade - as chamadas "Cidades UCA Total", são elas: Barra dos Coqueiros/SE, Caetés/PE, Santa Cecília do Pavão/PR, São João da Ponta/PA, Terenos/MS e Tiradentes/MG.

Num país de proporções continentais como o Brasil, onde as longas distâncias mostram-se como impedimentos na implantação das redes de comunicação, a iniciativa de estabelecer o PROUCA em sua totalidade em determinadas regiões é traduzida como uma tentativa de visualizar o potencial desta ação quando esta vir a se tornar uma realidade nacional.

Ao considerarmos que um município esta sendo atendido em sua totalidade, infere-se que todos os seus estudantes estão sendo abarcados pela oferta de laptops. De acordo o IBGE, 14,5\% da população brasileira apresenta algum tipo de necessidade especial. Portanto, temos mais de vinte e sete 
milhões de pessoas que se incluem esta parcela da sociedade. Boa parte deste público apresenta-se em idade escolar e por isso devem ser contemplados pelas ações que visam sua aplicabilidade neste contexto.

Observamos que as ferramentas disponibilizadas através do Projeto UCA podem ajudar a romper com a lógica racionalista excludente. Valente (1991) pontua que o motivo principal para este rompimento é que as TICs são ferramentas do processo de aprendizagem, capazes de:

"Propiciar aos sujeitos a oportunidade de
desenvolverem atividades interessantes, desafiantes e
que tenham propósitos educacionais. Estas atividades
podem oferecer a eles a chance de construir
conhecimento e sobrepujar suas deficiências
intelectuais" (VALENTE, 1991 p 01).

O computador tem a capacidade de transformar as condições de vida de uma pessoa com necessidades especiais, possibilitando desde a comunicação até o seu desenvolvimento intelectual. Utilizá-lo por meio dos recursos acessíveis constitui-se como uma grande contribuição para que possam realizar as mesmas atividades que todas as outras pessoas.

Pesquisas evidenciam a relevância do trabalho com a informática na educação no processo de desenvolvimento de pessoas com deficiência. Segundo a Prof. Dra. Lucila Maria Costi Santarosa (2002), a informática tem sido uma grande aliada destes sujeitos, proporcionando a quebra de obstáculos e a transposição de barreiras. Esta professora embasa sua afirmação nos resultados das diferentes pesquisas que vem realizando junto ao Núcleo de Informática na Educação Especial - NIEE, do qual é fundadora e coordenadora ao longo das últimas décadas. Tais resultados indicam que as TICs abrem portas, amenizando a discriminação social diminuindo a segregação ao proporcionar que todos possam demonstrar suas capacidades. Propiciam um espaço de oportunidades, principalmente para as pessoas cujos padrões de aprendizagem não seguem os quadros típicos de desenvolvimento. Neste sentido, Santarosa pontua que:

"Entrelaçar tecnologias digitais de informação e comunicação com um qualificado plano pedagógico impulsiona um ajuste às especifidades e a variedade de histórias de vida de sujeitos em processo educativo, um respeito que valoriza a diversidade humana e permite que a heterogeneidade seja lida com vantagem e não como prejuízo." (SANTAROSA E OUTROS, 2010 p 21) 
É necessário observarmos que atualmente a educação brasileira segue os preceitos da Política Nacional de Educação Especial na Perspectiva da Educação Inclusiva (2008). Desta forma, é preciso assegurar que um projeto de oferta de tecnologias como o UCA voltados à educação apresentem em sua origem o cuidado para que o acesso a ele abarque a diversidade humana.

\section{A Política Nacional de Educação Inclusiva}

O Ministério da Educação, fortemente influenciado pelos documentos internacionais inclusivos, dentre eles a Declaração de Salamanca e a Convenção sobre os Direitos das Pessoas com Deficiência (ONU/2006), propõe-se a desenvolver programas, projetos e ações a fim de implementar no país a Política Nacional de Educação Especial na Perspectiva da Educação Inclusiva (2008).

Nesta nova visão, pretende-se assegurar a inclusão de alunos com deficiência, transtornos globais do desenvolvimento e altas habilidades/superdotação, tendo por objetivo o acesso, a participação e a aprendizagem destes alunos, orientando os sistemas de ensino a promoverem respostas às necessidades educacionais especiais, através de diferentes diretrizes. Dentre elas, é prevista a oferta de um Atendimento Educacional Especializado - AEE, as diretrizes estabelecem que este:

\footnotetext{
"identifica, elabora e organiza recursos pedagógicos e de acessibilidade que eliminem as barreiras para a plena participação dos alunos, considerando as suas necessidades específicas." (BRASIL 2008:16)
}

Cabe a este atendimento organizar recursos que propiciem a participação dos alunos em aula, considerando as especificidades de cada um. Ressalta-se que ele não deverá substituir as atividades de escolarização, mas sim suplementar as atividades por este previstas.

Inclusão, em seu sentido etimológico, significa compreender, conter e fazer parte. Por isso, falar de uma escola inclusiva significa dizer que todos os seus alunos participam de suas dinâmicas efetivamente. Tais idéias se assemelham muito com as proposições de reforma escolar que Vygotsky já realizava no século passado. Este autor defendia que pessoas com deficiência devem fazer parte do sistema educativo regular, visando o seu 
desenvolvimento integral enquanto sujeito. Ele defendia também a existência de um ambiente 'auxiliar', que deveria dar suporte a escola regular, de forma totalmente integrada, mas sempre se orientando para o desenvolvimento da pessoa e não para enfatizar a deficiência.

\begin{abstract}
'O ensino 'especial' deve perder seu caráter 'especial' e somente assim passará a ser parte da função educativa comum. A escola auxiliar, criada só como ajuda à escola normal, não deve romper nunca nem em nada os vínculos com ela [...] Deve se orientar para a normalidade, desterrar por completo tudo o que agrava o defeito".( VYGOTSKY, 1997:84 )
\end{abstract}

Neste sentido, identificamos a escola inclusiva prevista na legislação, como um avanço na história da educação especial. Contudo, ressaltamos que há que se ter atenção para que a inclusão não garanta apenas o livre acesso à escola regular.

\title{
O cruzamento de Políticas em contexto escolar
}

Relacionando os elementos teóricos apresentados neste artigo, podemos construir um panorama caracterizando hoje nossa sociedade por um lado inclusiva por outro uma sociedade tecnológica. Ambos os temas se entrecruzam quando abordamos questões relacionadas à escola atual. Esta instituição vem sofrendo modificações concomitantes visando abarcar a diversidade em seu sistema regular e também vem respondendo às políticas que prevêem a oferta de laptops para cada aluno vinculado a este contexto.

Com o objetivo de observar os movimentos desencadeados no processo de inclusão de alunos com deficiência, mediados por laptops do programa um computador por aluno na experiência piloto de uma cidade UCA Total, iniciouse uma pesquisa qualitativa, descritiva em formato de estudo de caso, enfocando a realidade de Tiradentes-MG.

A pesquisa encontra-se na etapa de identificação das situações de inclusão no município. Para tanto, foram realizadas entrevistas semiestruturadas com o gestor municipal de educação, com os diretores das escolas e professores da rede de ensino de Tiradentes-MG. Também foi realizada a analise documental e uma observação "in loco" de forma direta por uma semana, período em que foram observadas as realidades de cada uma das 7 escolas deste contexto (6 municipais e 1 estadual) 


\section{Avaliação preliminar do contexto em geral.}

Primeiramente, é necessário observar que o município de Tiradentes já dispõe no número de laptops necessários para atendimento da rede regular de ensino em sua totalidade. Entretanto, algumas fragilidades estão impedindo a efetiva utilização dos recursos disponíveis.

A falta de sinal de Internet é apontada como a causa da não utilização dos laptops em uma das escolas de contexto rural. Por se tratar de uma região isolada e sem cabeamento, tal recurso só poderá ser disponibilizado via satélite. Contudo, a prefeitura não dispõe de verbas para licitações desta natureza. Ao apontarmos o uso dos softwares do próprio laptop como solução momentânea para a utilização das tecnologias, somos apresentados a uma outra fragilidade: - A falta de capacitação dos professores.

O município de Tiradentes realizou recentemente um concurso para a área da educação. Os professores aprovados foram nomeados somente após a realização da formação inicial presencial prevista para este projeto. A diferenciação do sistema operacional com o qual estão habituados e 0 desconhecimento das potencialidades pedagógicas da tecnologia disponível são apontados como razões para a não utilização do laptop sob a circunstância da falta de Internet.

Outra fragilidade foi encontrada em uma sala de aula de uma das escolas em contexto urbano. Esta não dispõe de local de armazenamento para as tecnologias, contrapartida exigida pelo MEC para a utilização dos laptops.

Com este mesmo problema de armazenamento a escola estadual encontra-se em uma situação mais alarmante. O conflito entre o prédio histórico e o avanço tecnológico é apontado como um dos motivos do atraso das obras que resultaram na não distribuição dos laptops neste contexto. "Tudo aqui é histórico, para fazer uma reforma não é simples. Temos a questão do prédio tombado" disse a diretora da escola justificando o fato de que todos os laptops ainda encontram-se encaixotados aguardando a montagem de locais de armazenamento. 


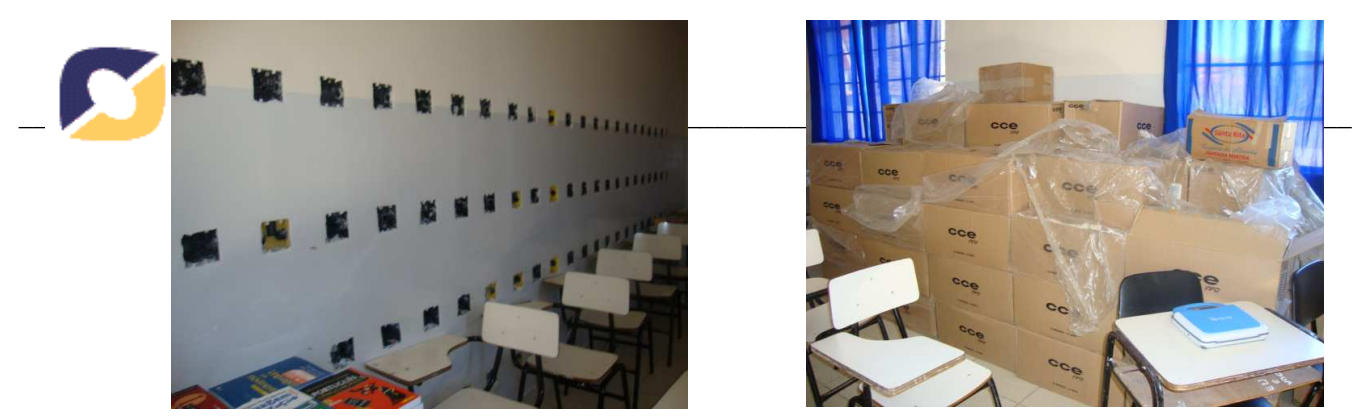

Futuro local de armazenamento dos laptops

Laptops encaixotados

Dentre os contextos que estão fazendo uso da tecnologia, identifica-se como fragilidade nesta etapa inicial que nenhum dos alunos esta levando seu laptop para casa, ação que é prevista na redação do projeto UCA. A secretaria de educação do município alerta que pretende autorizar esta ação assim que todos os alunos estiverem interagindo com a tecnologia e que estiverem habituados com a proposta do projeto.

Finalmente aponta-se a padronização do uso como um dos aspectos negativos identificados nos contextos que já fazem uso do laptop. Diversos são os professores que relataram utilizar a tecnologia com suas turmas em dias previamente determinados, não se libertando ainda do paradigma tempo e espaço para a utilização da tecnologia herdado da época em que faziam uso dos laboratórios de informática. Muitos usam este "dia de utilização dos laptops" como barganha no cumprimento de atividades ou como política de bom comportamento, sendo o seu uso prêmio aos alunos que cooperam.

Por outro lado, já é possível observar a ventilação de iniciativas de sucesso mediadas pela tecnologia. Uma das professoras é citada como exemplo por ter utilizado o laptop com sua turma ao realizar um trabalho de campo sobre os monumentos históricos da região. Seus alunos utilizaram os recursos da webcan como máquina fotográfica e o editor de texto como registro de pesquisa.

Um destaque positivo unânime entre os professores e gestores é relativo à motivação dos alunos em interagirem com a tecnologia. Os contextos que já fazem uso dos laptops demonstram que o índice de evasão, que já era baixo, tornou-se ainda menor após a disponibilização dos computadores.

Como aspecto positivo, a maioria dos professores que já estão utilizando a ferramenta, relatam a rápida manutenção dos equipamentos que por ventura venham a ter problemas. Esta manutenção é feita no próprio município sendo devolvido o laptop em tempo médio de 4 dias úteis. 


\section{A análise da Totalidade - Resultados parciais}

Para identificar os casos de inclusão no município, solicitou-se inicialmente ao departamento de educação uma lista de alunos que apresentavam necessidades especiais, bem como relatórios e laudos. Após avaliação deste levantamento, 20 professores foram entrevistados, e deste universo 9 responderam ao questionário solicitado.

Os dados parciais apontam que os alunos atendidos por estes 9 professores são caracterizados como: $1 \mathrm{com}$ deficiência mental que freqüenta a APAE em turno inverso, 3 com baixa visão, 2 com transtornos de desenvolvimento oriundos da APAE, 1 com síndrome de Erlin, 1 com TDAH e dislexia e 5 alunos que foram encaminhados aos especialistas por apresentarem dificuldades de aprendizagem combinadas com outras características, sendo que um deles já é acompanhado pela APAE em turno inverso.

Observando este primeiro dado podemos ressaltar os esforços do município em responder às prerrogativas da Política de Educação Inclusiva. Já se identificam 2 casos em que os alunos são freqüentadores da escola regular e utilizam o suporte da APAE em turno inverso ao de sua escolarização. Sobre este aspecto a Secretária de educação do município destacou em entrevista que existe apenas uma criança com a qual não houve nenhuma tentativa de inserção na rede regular de ensino, sendo esta uma opção da mãe que por trabalhar na APAE fez questão de matriculá-lo neste local. Com todas as outras ao menos uma tentativa de inclusão foi feita.

Ao entrevistamos os professores dos 2 alunos freqüentadores da APAE. Observamos que ambos ressaltaram a importância tanto do atendimento especializado ofertado naquele ambiente quanto a freqüência destes alunos na rede regular, nem que seja apenas para sua socialização. Alem disso, os professores destacam que percebem maiores progressos, dentre os alunos especiais, naqueles que estão nesta situação de duplo atendimento.

De outra banda, perguntamos aos 9 professores se eles se sentem preparados para trabalhar com as situações inclusivas em sala de aula. Deste universo, 5 professores responderam que sim, mas ressaltam a importância de um maior apoio por parte do atendimento especializado e 4 professores 
responderam negativamente a esta questão apontando a falta de uma capacitação na área como justificativa para a afirmação.

Ao citarmos o uso do laptop em sala de aula, cabe salientar que destes 9 professores apenas 2 realizaram a formação presencial inicial do projeto e continuam realizando-a à distância. Uma delas é a professora que esta sem o local de armazenamento das tecnologias e que por esse motivo ainda não esta utilizando o laptop com seus alunos. Desta forma, o uso do laptop educacional, na maioria dos casos, ainda esta tendo um caráter experimental e a descoberta das potencialidades da tecnologia esta se dando em mesmo tempo, tanto para os alunos quanto para os professores.

Em relação à questão da tecnologia para a realidade inclusiva, perguntamos se os professores identificam dificuldades por parte destes alunos ao interagirem com o laptop. Um deles aponta que seu aluno com dificuldade de aprendizagem demonstra certa irritabilidade ao não concluir uma tarefa proposta, e identifica esta situação não só nas interações com o laptop, mas sim na utilização de qualquer suporte pedagógico visto que ele ainda não esta "totalmente" alfabetizado. Por outro lado, 6 professores pontuam que seus alunos com necessidades especiais apresentam as mesmas dificuldades que os demais colegas. Sendo que um dos professores pontua que em dada situação o aluno com dificuldades de aprendizagem já até assumiu o papel de mediador de seus colegas frente a uma dificuldade. Foi pontuado por 2 dos professores que atendem alunos com baixa visão que o uso efetivo da tecnologia é prejudicado devido ao tamanho do laptop disponível, mas que com esforço eles não deixam de utilizá-lo.

Este esforço é traduzido pelos professores como uma motivação para o uso das tecnologias. Todos destacam a vontade deste publico em interagir com o laptop. Uma das professoras em entrevista ressaltou: "tem coisas que minha aluna não faz se for numa atividade normal, mas se eu falar que vamos utilizar o computador ela se vira".

Por fim, perguntamos se os professores tinham conhecimento de instrumentos que possibilitariam um melhor uso do laptop por parte destes alunos. Dos 9 professores apenas uma respondeu ter conhecimento de um programa de aumento de letras que poderia ser disponibilizado ao seu aluno 
com baixa visão. Os demais desconhecem as possibilidades das tecnologias assistivas.

\section{Considerações Finais}

Cabe salientar que estes dados farão parte de uma pesquisa maior que, sob o enfoque Vygotskyano, pretende observar quais mudanças ocorrem nas dimensões cognitivas e sociais de pessoas com deficiência quando mediadas por laptops em contexto escolar, bem como identificar quais movimentos inclusivos estão sendo desencadeados a partir da implementação do PROUCA, tanto nas dinâmicas de sala de aula e nas escolas quanto na gestão educacional do município.

No que tange a disponibilização dos recursos, podemos afirmar que os alunos especiais estão acompanhando o status de implementação do projeto da turma em que se encontram. Todos que estão matriculados em contextos que já estão fazendo o uso do laptop receberam os seus equipamentos também, não havendo nenhum caso de diferenciação ou segregação tecnológica. Entretanto, por tudo que foi posto, inferimos nesta etapa de pesquisa que a totalidade no município de Tiradentes, sendo ela inclusiva ou não, ainda não foi alcançada devido aos entraves burocráticos decorrentes dos problemas de infraestrutura. Portanto, longe de abarcar efetivamente a diversidade humana neste contexto, a cidade UCA Total de Tiradentes luta hoje para garantir a oferta dos laptops a toda sua rede de ensino regular.

\section{Referências bibliográficas} Inclusiva,

BRASIL, Política Nacional de Educação Especial na Perspectiva da Educação http://portal.mec.gov.br/arquivos/pdf/politicaeducespecial.pdf. Acessado em 10/11/2010

SANTAROSA, L.M.C. Ambientes de Aprendizagem Virtuais: inclusão social de portadores de necessidades especiais. Porto Alegre: UFRGS, 2002.

JSM, 2010

(Org).Tecnologias Digitais Acessíveis - Porto Alegre,

VALENTE, J.A. (Org.). Liberando a Mente: computadores na educação especial - Campinas - Unicamp, 1991.

VYGOTSKY, L. S. Obras escogidas V: fundamentos de defectologia. Madrid: Visor, 1997

MISSÃO One Laptop per Child. Base de Dados OLPC: no ar desde 2007. Disponível em: < http://one.laptop.org/about/mission >. Acesso em: 30 mai. 2011. 